\title{
Clinical and Neuropsychological Characteristics of a Nationwide Hospital-Based Registry of Frontotemporal Dementia Patients in Korea: A CREDOS-FTD Study
}

\author{
Eun-Joo Kim ${ }^{a}$ Kyung-Won Park ${ }^{b}$ Jae-Hong Lee ${ }^{c}$ SeongHye Choig \\ Jee H. Jeong ${ }^{d}$ Soo Jin Yoon ${ }^{\mathrm{h}}$ Byeong C. Kim ${ }^{\mathrm{i}}$ Jay C. Kwon ${ }^{\mathrm{j}}$ Bon D. Ku ${ }^{\mathrm{k}}$ \\ Seung Hyun Kim ${ }^{e}$ Byung-Ok Choi ${ }^{f}$ Duk L. Na ${ }^{f}$ \\ ${ }^{a}$ Department of Neurology, Pusan National University Hospital, Pusan National University \\ School of Medicine and Medical Research Institute, and ${ }^{b}$ Department of Neurology, Dong-A \\ Medical Center, Dong-A University College of Medicine, Busan, 'Department of Neurology, \\ Asan Medical Center, University of Ulsan College of Medicine, ${ }^{d}$ Department of Neurology, \\ Ewha Womans University Mokdong Hospital, Ewha Womans University School of Medicine, \\ e Department of Neurology, Hanyang University College of Medicine, and ${ }^{\mathrm{f}}$ Department of \\ Neurology, Samsung Medical Center, Sungkyunkwan University School of Medicine, Seoul, \\ ${ }^{9}$ Department of Neurology, Inha University School of Medicine, Incheon, ${ }^{\mathrm{h}}$ Department of \\ Neurology, Eulji University Hospital, Eulji University School of Medicine, Daejeon, 'Department \\ of Neurology, Chonnam National University Medical School, Gwangju, jDepartment of \\ Neurology, Changwon Fatima Hospital, Changwon, and kDepartment of Neurology, College of \\ Medicine, Kwandong University Myongji Hospital, Goyang, Korea
}

\section{Key Words}

Frontotemporal dementia · Demography · Epidemiology · Asia · Korea

\begin{abstract}
Background: We investigated the demographic, clinical, and neuropsychological characteristics of frontotemporal dementia (FTD) from the Clinical Research Center for Dementia of South Korea (CREDOS)-FTD registry. Methods: A total of 200 consecutive patients with FTD recruited from 16 neurological clinics in Korea were evaluated by cognitive and functional assessments, a screening test for aphasia, behavioral questionnaires, motor assessments, and brain MRI or PET. Results: In our registry, 78 patients were classified as having been diagnosed with behavioral-variant FTD (bvFTD), 70 with semantic dementia (SD), 33 with progressive nonfluent aphasia (PNFA), and 8 with motor neuron disease plus syndrome (MND-plus). The patients with language variants of dementia were older than those with bvFTD. There were no differences in sex ratio, duration of illness, or level of education among the four subgroups. Overall, the patients with bvFTD showed a significantly better performance in cognitive tests.
\end{abstract}


A higher frequency of motor symptoms and a lower frequency of behavioral symptoms were found in PNFA than in bvFTD and SD. The Global Language Index was significantly lower in SD than in bvFTD and PNFA. The MND-plus group had a poorer performance than all the others in all cognitive domains. Conclusion: The neuropsychological, behavioral, motor, and language characteristics of the four subtypes are comparable with those from other series. However, the proportion of SD (37.0\%), which was similar to that of bvFTD (41.3\%), was higher in our registry than in other series.

\section{Introduction}

Frontotemporal dementia (FTD) may be as common as Alzheimer's disease (AD) in earlyonset neurodegenerative dementia before the age of 60 years [1]. It has three clinical subtypes distinguished by their clinical presentation: behavioral-variant FTD (bvFTD), presenting with a progressive deterioration in social functioning and personality, and two language variants, semantic dementia (SD) with semantic anomia and progressive nonfluent aphasia (PNFA) with effortful, halting, and agrammatic speech [2-7]. Up to 14\% of patients with FTD might show symptoms overlapping with those of motor neuron disease (MND) [8].

A few epidemiological studies on FTD showed a wide variety of results according to their recruitment setting, such as whether they were clinic based or community based [1, 9-19]. These differences in epidemiology may also vary according to ethnic populations. However, there are only limited epidemiological data on FTD available from Asian populations [13, 16, 17].

The Clinical Research Center for Dementia of South Korea (CREDOS), a governmentfunded dementia research project conducted by dementia specialists from neurological and psychiatric clinics, initiated a longitudinal registry study on FTD (the CREDOS-FTD study) in 2010, in addition to a CREDOS registry study on AD and vascular dementia [20].

In our study, we explored the demographic, neuropsychological, and neuropsychiatric characteristics of a large group of Korean FTD patients from the CREDOS-FTD registry. The purpose was to identify significant variations in epidemiology among Korean patients with FTD compared with those among Caucasian or other Asian populations. To our knowledge, this is the first nationwide hospital-based registry study of FTD in Korea.

\section{Materials and Methods}

\section{Participants}

Sixteen neurological clinics across Korea participated in this CREDOS-FTD registry study. All patients enrolled in this study met the research criteria for FTD proposed by Knopman et al. [21] and were subclassified into bvFTD, SD, or PNFA. To fulfill the clinical criteria for the FTD subtypes, the patients were first required to have a predominance of a frontal or temporal lobe cognitive/behavioral syndrome without or with only insignificant anterograde amnesia and visuospatial impairment within the first 2 years of symptoms. Additionally, imaging studies demonstrating focal cerebral atrophy of at least one of the following were required: the anterior temporal lobes, the frontal lobes, and the insula or caudate nuclei. Thus, all patients underwent brain MRI, and almost half of the patients were examined by $\left[{ }^{18}\right.$ F]fluoro-2-deoxy-D-glucose PET. Patients who had clinical and electrophysiological evidence of MND were classified as having 'MND plus syndrome' (MND-plus) regardless of their clinical subtypes of FTD. The disease severity was assessed by the FTD-specific Clinical 
Dementia Rating (FTD-CDR), including 2 domains (i.e., behavior and language) in addition to the 6 standardized domains of the CDR [21].

All patients were evaluated by comprehensive interviews, neurological examinations, and neuropsychological assessment, as described elsewhere [20]. In brief, caregivers were interviewed in depth by neurologists and neuropsychologists. Patients with current or past neurological or psychiatric illnesses such as schizophrenia, epilepsy, brain tumors, encephalitis, or severe head trauma were excluded. Patients with physical illnesses that could interfere with the clinical study, such as hearing or vision loss, severe cardiac disorders, severe respiratory illnesses, malignancy, or hepatic or renal disorders, were excluded. Blood tests to exclude secondary causes of dementia included a complete blood count, blood chemistry tests, vitamin $\mathrm{B}_{12}$ /folate, syphilis serology, and thyroid functioning tests. Conventional brain MRI scans confirmed the absence of structural lesions such as tumors, traumatic brain injuries, hydrocephalus, or severe white matter hyperintensities.

\section{Clinical Evaluations}

We used the FTD Evaluation Package developed by CREDOS, which is composed of the Clinical Evaluation Form and the Caregiver Questionnaire Form. The Clinical Evaluation Form includes the following: (1) a history of cognitive decline from the caregiver, (2) a Mini-Mental State Examination (MMSE) score [22], (3) an FTD-CDR sum of boxes (FTD-CDR SB) score [21], (4) a Global Deterioration Scale (GDS) score [23], (5) a Hachinski Ischemia Scale (HIS) score [24], (6) a neurological examination, (7) a Geriatric Depression Scale score [25], and (8) a Unified Parkinson's Disease Rating Scale (UPDRS) Part III score [26].

The Caregiver Questionnaire Form includes each of the following: (1) basic demographic data about the patient and caregiver, (2) a lifestyle and family history, (3) a past medical history including vascular risk factors, (4) a Korean Dementia Screening Questionnaire (KDSQ) score [27], (5) a Barthel ADL index [28], (6) a Seoul Instrumental ADL (SIADL) score [29], (7) a Caregiver-Administered Neuropsychiatric Inventory (CGA-NPI) score [30], (8) a Frontal Behavioral Inventory (FBI) score [31], and (9) a Frontal Executive Dysfunction, Disinhibition, and Apathy Scale (FEDAS) score [32].

We categorized the presenting symptoms of the patients into one of the following three types: abnormal behavior, aphasia, and motor disturbance. In addition to the family history of dementia, we investigated whether patients had a family history of Parkinson's disease, MND, or psychiatric disorders.

A committee that included 5-10 dementia specialists held a quarterly meeting to review the clinical histories and brain imaging results of all cases enrolled in this study and to reach a consensus which ascertained the clinical diagnosis. The institutional review boards at all participating centers approved this study, and informed consent was obtained from the patients and caregivers.

\section{Neuropsychological Assessment}

All patients underwent a standardized neuropsychological test battery known as the cognitive test battery for FTD (FTD-Cog), consisting of subdomains assessing attention, language and related function, visuospatial function, memory, and frontal/executive function (table 1). We constructed an FTD-Cog Score of a maximum of 312 points derived from the results of the FTD-Cog tests which is the sum of each subdomain, with $8 / 312$ points $(2 \%)$ from attention, 90/312 (29\%) from language and related function, 37/312 (12\%) from visuospatial function, 60/312 (19\%) from memory, and 117/312 (38\%) from frontal/executive function.

The attention domain score was derived from only the raw score for backward digit span. The raw scores of the Korean version of the Boston Naming Test (K-BNT) [33] and of the 
Table 1. The FTD-Cog and constructed FTD-Cog Score

\begin{tabular}{lc}
\hline FTD-Cog & FTD-Cog Score (maximum points) \\
\hline Attention & Attention (8) \\
Digit span, forward and backward & Digit span, backward (8) \\
Language and related function & Language and related function (90) \\
K-BNT & K-BNT (60) \\
STAND & GLI of the STAND (30) \\
Visuospatial function & Visuospatial function (37) \\
RCFT, copy & RCFT, copy (36) \\
Letter cancellation & Letter cancellation (1) \\
Memory & Memory (60) \\
SVLT, free/delayed recall & SVLT, free/delayed recall (48) \\
SVLT, recognition & SVLT, recognition (12) \\
Frontal/executive function & Frontal/executive function (117) \\
Motor impersistence & Motor impersistence (3) \\
Contrasting program & Contrasting program (3) \\
Go/no-go & Go/no-go (3) \\
Fist-edge-palm & Fist-edge-palm (3) \\
Luria loop & Luria loop (3) \\
Category word fluency, animal/supermarket & Category word fluency, animal (20) \\
Phonemic word fluency ( $7,0, \lambda)$ & Phonemic word fluency ( 7 ) (15) \\
Stroop test, word/color reading & Stroop test, color reading (20) \\
Verbal similarities & Verbal similarities (10) \\
Digit symbol substitution & Digit symbol substitution (17) \\
Trail Making & Trail Making (20) \\
\hline
\end{tabular}

The maximum FTC-Cog Score is 312.

Global Language Index (GLI) of the Screening Test for Aphasia and Neurologic Communication Disorders (STAND) - the latter of which was the sum of the scores for the 6 subtests of picture description (3), naming (4), auditory comprehension (10), repetition (3), reading (7), and writing (3) - made up the score of the language and related function domain.

The copy test from the Rey Complex Figure Test (RCFT) and a letter cancellation test were administered to evaluate visuospatial function. The letter cancellation test was drawn from the Seoul Neuropsychological Screening Battery (SNSB) [34] and rated ' 1 ' if a patient performed normally or ' 0 ' if a patient showed hemispatial neglect or any errors.

The memory function score resulted from the sum of 3 recall trials, a delayed-recall task, and a recognition task from the Seoul Verbal Leaning Test (SVLT). Frontal/executive function was evaluated using a motor impersistence test, a contrasting program test, a go/no-go test, a fist-edge-palm task, and a Luria loop task, each of which were rated on a 0-3 scale. In addition, a category word fluency test, a Stroop color-reading test, a verbal similarities test, digit symbol substitution tasks from the Korean Wechsler Adult Intelligence Scale (K-WAIS) [35], and a Korean version of the Trail Making Test for the elderly (K-TMT-e) [36] were administered. Regarding word fluency, a category word generation task (animal) and a phonemic word fluency task ( $\neg$ ' /g/) were conducted, with a maximum score of 20 for the category word generation task and of 15 for the phonemic word generation task. Thus, if the number of appropriate words generated was greater than 20 or 15, respectively, the measure was scored as 20 or 15 points. The Stroop color-reading test score was converted to a maximum score of 20 by dividing the number of correct responses by 5 and rounding down to the nearest whole number. Five verbal similarities subtests were chosen from the K-WAIS, 
and the maximum score of each subtest was 2. For the K-TMT-e, the time in seconds (B) needed to complete part B was recorded. Since $60 \mathrm{~s}$ was the average time needed for a normal elderly subject to finish part B, 60 was divided by B and then multiplied by 20 to determine the conversion score. The digits after the decimal points were dropped. If $\mathrm{B}$ was shorter than $60 \mathrm{~s}, 60 / \mathrm{B}$ was regarded as 1, and if B was longer than 3,000 s, 60/B was regarded as 0 .

\section{Results}

\section{Demographics}

Two hundred patients were initially enrolled in the CREDOS-FTD registry between January 2010 and March 2012. Eleven patients with uncertain clinical diagnoses were excluded from the analysis to ensure data set homogeneity. The remaining 189 patients were composed of 78 bvFTD (41.3\%), 70 SD (37.0\%), 33 PNFA (17.5\%), and 8 MND-plus patients $(4.2 \%)$ who showed various presenting symptoms ( 2 with both aphasia and motor impairment, 3 with abnormal behavior, and 3 with motor impairment). The sexes were equally divided between all subtypes $(p=0.959)$. The age at onset $(p=0.049)$ and the age at diagnosis $(p=0.029)$ differed between the diagnostic subtypes; however, there were no significant differences in duration and education between the diagnostic subgroups $(\mathrm{p}=0.238$ and $\mathrm{p}=$ 0.762 , respectively).

A history of dementia in first-degree relatives (parents and siblings) was found in $20.9 \%$ $(24 / 115)$ of the patients with FTD. Even though there was no significant difference in family history between the three subtypes, the PNFA group was less likely to have a positive family history of dementia (9.1\%) than the bvFTD (25\%) and the SD (23.3\%) groups. Only 2 and 5 patients with FTD had a positive family history of Parkinson's disease and psychiatric disease, respectively. No patient with FTD demonstrated a family history of MND. In terms of ADL, the MND-plus group showed significantly impaired functional abilities as assessed by the SIADL and KDSQ compared with both the PNFA and SD groups, but not compared with the bvFTD group. Of the four groups, physical ADL were most significantly impaired in the MND-plus group ( $\mathrm{p}=0.009$; table 2$)$.

\section{Neuropsychological Test Results}

The patients with bvFTD showed a significantly better performance on the K-MMSE compared with the SD group ( $\mathrm{p}=0.013)$. The patients with PNFA also had better K-MMSE scores than the SD group, although the difference was not significant. The CDR $(p=0.008)$ and the CDR SB ( $p=0.039)$ scores were significantly the highest in patients with MND-plus. However, there were no significant differences in FTD-CDR SB and GDS scores between the four groups ( $p=0.056$ and $p=0.056$, respectively). Figure 1 shows the results from the 5 subdomains of the FTD-Cog for the four groups. The SD group had a significantly poorer language function than both the bvFTD $(\mathrm{p}<0.001)$ and PNFA groups $(\mathrm{p}<0.001)$. The PNFA patients showed a significantly more impaired language function than the bvFTD patients $(p=0.049)$. While the memory function of the SD patients was impaired in relation to the bvFTD and PNFA patients, their visuospatial function was greater than that of the bvFTD and PNFA patients. Regarding attention, no differences were seen between the groups. The MND-plus group had a poorer performance than all others in all cognitive domains (table 2; fig. 1). The FTD-Cog total scores differed significantly between the groups $(\mathrm{p}<0.001)$. Post hoc analyses revealed that the FTD-Cog total scores were significantly higher in the bvFTD group compared with the SD and the MND-plus groups, but not compared with the PNFA group. 
Kim et al.: Clinical and Neuropsychological Characteristics of a Nationwide HospitalBased Registry of Frontotemporal Dementia Patients in Korea: A CREDOS-FTD Study

Table 2. Comparison of demographic, neuropsychological, and neuropsychiatric data on FTD patients

\begin{tabular}{|c|c|c|c|c|c|c|}
\hline & $\operatorname{FTD}(\mathrm{n}=189)$ & bvFTD $(\mathrm{n}=78)$ & $\mathrm{SD}(\mathrm{n}=70)$ & PNFA $(n=33)$ & MND-plus $(\mathrm{n}=8)$ & $\mathrm{p}$ value \\
\hline Male & $55.6 \%$ & $57.7 \%$ & $54.3 \%$ & $54.5 \%$ & $50.0 \%$ & 0.959 \\
\hline Age at onset, years & $63.4 \pm 8.9(189)$ & $62.1 \pm 9.9(78)$ & $64.7 \pm 6.8(70)$ & $65.3 \pm 9.2(33)$ & $58.0 \pm 10.5(8)$ & 0.049 \\
\hline Age at diagnosis, years & $66.2 \pm 8.7(189)$ & $64.9 \pm 9.3(78)$ & $67.8 \pm 7.4(70)$ & $67.6 \pm 8.8(33)$ & $60.0 \pm 10.0(8)$ & 0.029 \\
\hline Duration, years & $3.0 \pm 2.1(189)$ & $3.1 \pm 2.3(78)$ & $3.4 \pm 1.9(70)$ & $2.5 \pm 2.3(33)$ & $2.5 \pm 1.2(8)$ & 0.238 \\
\hline Education, years & $9.3 \pm 5.4(186)$ & $9.5 \pm 5.8(78)$ & $9.2 \pm 5.1(68)$ & $9.7 \pm 5.5(32)$ & $7.5 \pm 3.9(8)$ & 0.762 \\
\hline \multicolumn{7}{|l|}{ Family history } \\
\hline Dementia & $20.9 \%(24 / 115)$ & $25 \%(12 / 48)$ & $23.3 \%(10 / 43)$ & $9.1 \%(2 / 22)$ & $0 \%(0 / 2)$ & 0.389 \\
\hline IPD & $1.1 \%(2 / 189)$ & $0 \%(0 / 78)$ & $2.9 \%(2 / 70)$ & $0 \%(0 / 33)$ & $0 \%(0 / 8)$ & 0.329 \\
\hline MND & $0 \%(0 / 188)$ & $0 \%(0 / 77)$ & $0 \%(0 / 70)$ & $0 \%(0 / 33)$ & $0 \%(0 / 8)$ & - \\
\hline Psychiatric disease & $2.6 \%(5 / 189)$ & $3.8 \%(3 / 78)$ & $1.4 \%(1 / 70)$ & $0 \%(0 / 33)$ & $12.5 \%(1 / 8)$ & 0.053 \\
\hline K-MMSE score & $17.6 \pm 8.3(183)$ & $19.6 \pm 6.8(78)^{\mathrm{a}}$ & $15.8 \pm 9.4(68)^{\mathrm{a}}$ & $17.6 \pm 8.6(30)$ & $12.3 \pm 6.6(7)$ & 0.013 \\
\hline CDR score & $1.0 \pm 0.7(183)$ & $1.0 \pm 0.7(78)^{\mathrm{a}}$ & $1.0 \pm 0.7(68)^{\mathrm{b}}$ & $0.9 \pm 0.7(29)^{\mathrm{c}}$ & $1.9 \pm 0.8(8)^{\mathrm{a}-\mathrm{c}}$ & 0.008 \\
\hline CDR SB score & $5.6 \pm 4.2(180)$ & $5.8 \pm 4.0(77)$ & $5.6 \pm 4.4(68)$ & $4.3 \pm 3.8(27)^{\mathrm{a}}$ & $9.1 \pm 4.7(8)^{\mathrm{a}}$ & 0.039 \\
\hline FTD-CDR SB score & $9.3 \pm 6.2(186)$ & $8.8 \pm 5.2(78)$ & $9.7 \pm 6.9(69)$ & $8.2 \pm 6.3(31)$ & $14.4 \pm 6.0(8)$ & 0.056 \\
\hline GDS score & $4.2 \pm 1.1(178)$ & $4.2 \pm 1.0(77)$ & $4.4 \pm 1.1(66)$ & $3.8 \pm 1.1(27)$ & $4.8 \pm 0.9(8)$ & 0.056 \\
\hline UPDRS score & $7.8 \pm 15.5(144)$ & $5.3 \pm 9.0(61)^{\mathrm{a}}$ & $6.4 \pm 16.9(52)^{\mathrm{b}}$ & $17.1 \pm 22.5(25)^{\mathrm{a}, \mathrm{b}}$ & $7.7 \pm 6.4(6)$ & 0.011 \\
\hline FBI score & $28.3 \pm 16.5(168)$ & $31.7 \pm 15.1(69)^{\mathrm{a}}$ & $27.5 \pm 17.8(62)$ & $20.3 \pm 15.5(29)^{a}$ & $33.5 \pm 13.0(8)$ & 0.013 \\
\hline CGA-NPI score & $21.5 \pm 20.3(173)$ & $29.0 \pm 23.5(73)^{a, b}$ & $17.2 \pm 15.3(67)^{\mathrm{a}}$ & $9.3 \pm 13.8(25)^{\mathrm{b}}$ & $27.8 \pm 15.3(8)$ & $<0.001$ \\
\hline FEDAS score & $56.4 \pm 30.6(173)$ & $64.3 \pm 26.6(73)^{\mathrm{a}}$ & $53.6 \pm 31.0(63)$ & $37.3 \pm 31.4(29)^{a, b}$ & $76.5 \pm 24.3(8)^{b}$ & $<0.001$ \\
\hline KDSQ score & $14.5 \pm 7.7(176)$ & $15.2 \pm 7.4(76)$ & $14.6 \pm 7.1(63)$ & $11.1 \pm 8.6(29)^{\mathrm{a}}$ & $20.5 \pm 7.7(8)^{\mathrm{a}}$ & 0.009 \\
\hline SIADL score & $17.5 \pm 12.4(176)$ & $19.5 \pm 11.6(77)$ & $15.3 \pm 12.2(63)^{\mathrm{a}}$ & $13.1 \pm 12.7(28)^{\mathrm{b}}$ & $30.3 \pm 8.7(8)^{a, b}$ & 0.001 \\
\hline Barthel ADL index & $18.2 \pm 3.4(181)$ & $18.0 \pm 3.0(77)^{\mathrm{a}}$ & $18.8 \pm 3.4(66)^{b}$ & $18.4 \pm 3.8(30)^{c}$ & $14.5 \pm 4.9(8)^{\mathrm{a}-\mathrm{c}}$ & 0.009 \\
\hline FTD-Cog total score [312] & $103.3 \pm 67.6(184)$ & $126.3 \pm 70.5(77)^{a, b}$ & $88.3 \pm 57.2(68)^{\mathrm{a}}$ & $93.7 \pm 68.0(31)$ & $47.5 \pm 47.3(8)^{b}$ & $<0.001$ \\
\hline FTD-Cog attention [8] & $2.6 \pm 3.9(161)$ & $3.1 \pm 5.7(70)$ & $2.5 \pm 1.6(59)$ & $1.8 \pm 1.3(27)$ & $2.0 \pm 1.6(5)$ & 0.480 \\
\hline FTD-Cog language [90] & $37.7 \pm 23.9(174)$ & $52.0 \pm 23.4(73)^{\mathrm{a}-\mathrm{c}}$ & $22.4 \pm 13.4(65)^{\mathrm{a}, \mathrm{d}}$ & $40.6 \pm 22.2(28)^{\mathrm{b}, \mathrm{d}}$ & $20.7 \pm 16.6(8)^{c}$ & $<0.001$ \\
\hline FTD-Cog visuospatial function [37] & $21.5 \pm 13.0(169)$ & $21.0 \pm 12.7(72)^{\mathrm{a}}$ & $25.7 \pm 11.1(61)^{\mathrm{b}, \mathrm{c}}$ & $17.6 \pm 13.7(28)^{\mathrm{b}}$ & $7.6 \pm 13.7(8)^{\mathrm{a}, \mathrm{c}}$ & $<0.001$ \\
\hline FTD-Cog memory [60] & $12.7 \pm 9.4(165)$ & $16.3 \pm 9.0(72)^{a, b}$ & $8.7 \pm 7.5(58)^{\mathrm{a}}$ & $13.3 \pm 10.3(27)$ & $7.6 \pm 10.1(8)^{b}$ & $<0.001$ \\
\hline $\begin{array}{l}\text { FTD-Cog frontal/executive function } \\
\text { [117] }\end{array}$ & $34.7 \pm 27.9(183)$ & $39.3 \pm 27.8(77)^{\mathrm{a}}$ & $34.6 \pm 28.6(67)$ & $29.6 \pm 26.2(31)$ & $9.8 \pm 10.4(8)^{\mathrm{a}}$ & 0.022 \\
\hline
\end{tabular}

Values denote means \pm SD unless specified otherwise. Figures in parentheses in the table body are available numbers for analysis. Figures in square brackets are maximum scores of the FTD-Cog test. ${ }^{\text {a-d }}$ Scores in each row are significantly different in pairwise comparison (Tukey post hoc test). IPD = Idiopathic Parkinson's disease.

\section{Neuropsychiatric and Motor Symptoms}

On the CGA-NPI, the bvFTD group scored significantly higher (more abnormal behavior) than the PNFA and the SD groups ( $<<0.001)$. However, on the FBI and FEDAS, the bvFTD group showed more behavioral abnormality than the PNFA group but was not different from the SD group. The PNFA patients had more parkinsonian symptoms, which were measured by the UPDRS motor scale, than the bvFTD and SD patients ( $\mathrm{p}=0.011$; table 2$)$.

\section{Discussion}

This is the first large epidemiological study in Asian FTD patients, though there have been three demographic FTD studies from Asian countries [13, 16, 17]. An epidemiologic study from Japan introduced a community-based trial and three hospital-based surveys of the typespecific prevalence of dementia, simply revealing the prevalence of FTD compared with that of AD and the proportion of each subtype of FTD without specific demographic, clinical, or neuropsychological data [13]. A recent study from China reviewed the clinical, demographic, and neuropathological features of 49 Chinese patients with FTD who had been previously reported on [17]. Kang et al. [16] investigated the survival of 121 Korean FTD patients from a single large neurological clinic in Korea, which therefore may not be representative of the true Korean FTD population.

One of the main observations of our study was that the proportion of SD (37.0\%) was similar to that of bvFTD (41.3\%). Even though Hodges et al. [6] reported that they found 110 


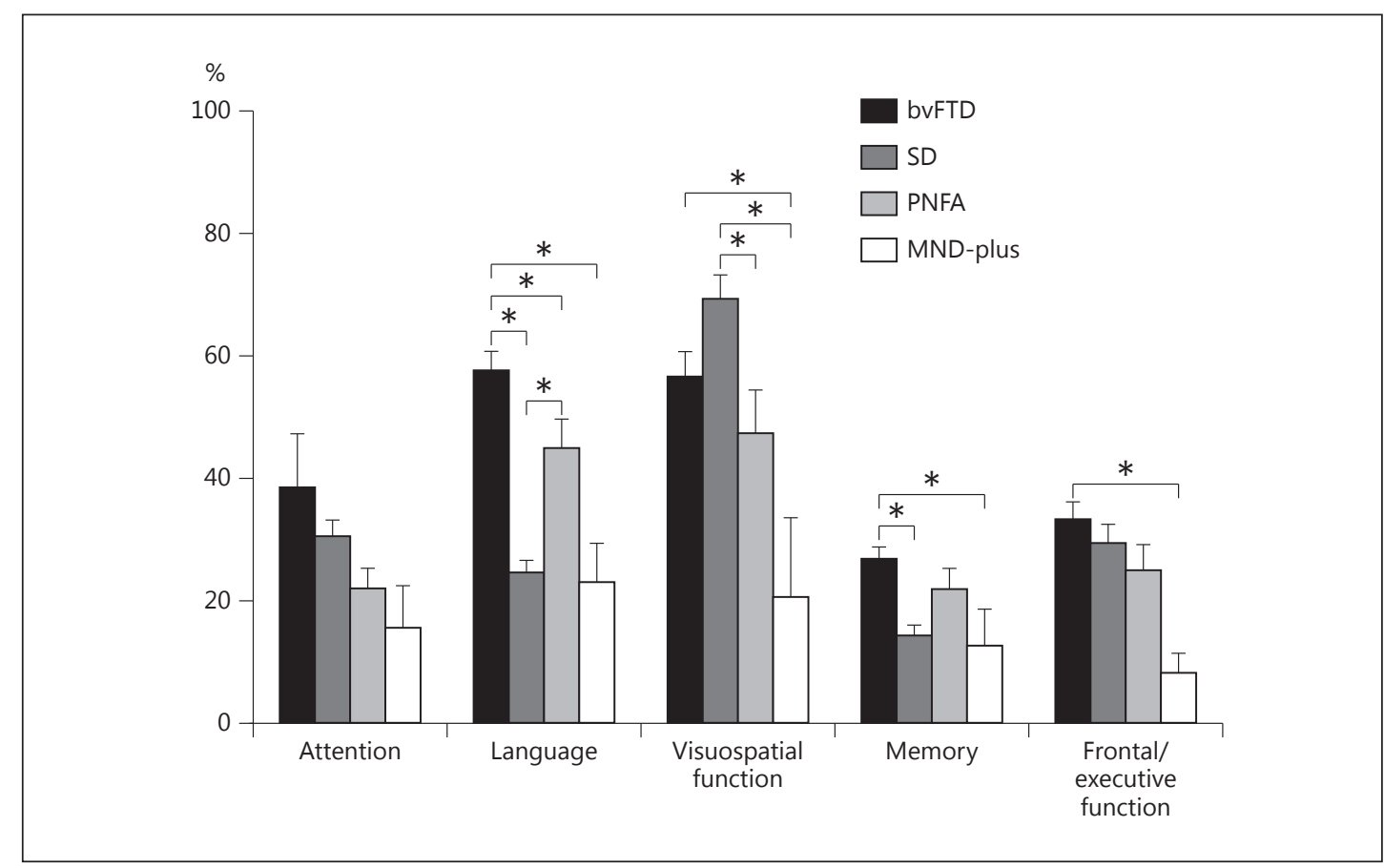

Fig. 1. Neuropsychological function of the four FTD subgroups on the FTD-Cog test. Raw scores are converted to percentages of the maximum score. ${ }^{*} \mathrm{p}<0.05$ by post hoc analyses between the groups.

SD patients in a sample of 304 FTD patients, which is a percentage similar to that found in our study, this proportion of SD cases is higher than that reported in most other series, in which bvFTD was the most common subtype, accounting for over half to three quarters of the FTD cases, whereas language variants were much less common [11,13,14,16-19]. The discrepancy in the proportions of FTD subtypes between our and other studies may be due to varying clinical settings. Chow et al. [37] compared referral patterns for FTD patients between specialized FTD clinics and standard AD clinics and demonstrated that language-variant FTD patients more often tended to be referred to specialist clinics. We assume that patients with bvFTD may be more frequently referred to psychiatric clinics than neurological clinics, while language-variant FTD patients are more frequently referred to neurological clinics. The centers that participated in the CREDOS-FTD registry study were all Korean neurological clinics specializing in dementia. In addition, specialists may identify SD more easily, since its clinical features and neuroimaging results tend to be homogeneous compared with other FTD subtypes.

In our study, the sex ratios were almost equal for all diagnostic subtypes. Although a few previous studies found a male predominance in patients with bvFTD and SD or a female predominance in all FTD subtypes $[13,14,16]$, most large series had an equal gender distribution as in our study $[10,37]$. The age at onset in our study differed between the clinical subtypes. The PNFA patients were slightly older at onset than the bvFTD and SD patients, which was similar to previous reports $[11,14,16,17]$.

Previous studies reported that the prevalence of a positive family history of dementia in first-degree relatives of FTD patients ranged from 20 to $50 \%$. More than $30 \%$ of FTD patients in Western countries had a positive family history [10,11], while lower proportions were seen among Asian FTD patients $[13,16,17]$. In our study, approximately $20 \%$ of the patients with FTD had a family history of dementia. Furthermore, a family history of MND, idiopathic Parkinson's disease, or psychiatric disease was quite rare in our series. 
The strength of the CREDOS-FTD registry study is that we assessed the FTD subjects using an optimized neuropsychological test (the FTD-Cog test). First, although the demographic factors including sex ratio, education, and disease stage measured by the FTD-CDR were not significantly different between the clinical subtypes, the MMSE score was lower in the language variants of FTD, particularly SD, unlike the results from Western countries [14]. This may be due to the heavy dependence on language skills in the MMSE [38]. Second, regarding the results of the FTD-Cog test, the SD subjects had a significantly poorer performance in the language and memory subdomains than the other two subgroups. These findings may be due to the deficits in single-word comprehension and verbal semantic knowledge in SD [39-41]. SD patients generally have a good day-to-day episodic memory; however, the verbal memory test may not reflect its preservation. Third, in contrast, visuospatial function (as assessed by the copy test of the RCFT) was selectively preserved in the SD group, which is compatible with the classic diagnostic criteria for SD [2]. A previous report suggests that PNFA patients have preserved visuospatial function [41]; however, a remarkably poor performance was evident in our study.

Here, we applied three behavioral measures to detect abnormal behaviors in FTD, and the results from each questionnaire were similar. The patients with bvFTD demonstrated the most severe behavioral deficits of the three groups, followed by the SD patients. The PNFA group showed the least behavioral abnormalities. These results support previous descriptions suggesting that SD is associated with behavioral abnormalities early in the course of the disease similar to those observed in bvFTD, which is likely due to anatomic involvement of the ventromedial frontal area (orbitofrontal area) as well as the anterior temporal pole in the early stage of SD [41-43]. Given that PNFA frequently evolves into corticobasal syndrome or progressive supranuclear palsy, it is not surprising that, among the three groups, the frequency and severity of parkinsonism as assessed by the UPDRS motor scale were highest in the PNFA group $[44,45]$.

Our study has limitations in that the clinical diagnoses of our patients have not been pathologically confirmed. Also, we acknowledge that there might have been some referral bias, since all 16 centers participating in our study were neurological clinics. However, our study is the first to describe the clinical, demographic, neuropsychological, and behavioral characteristics of a large population of Asian FTD patients by an optimized assessment.

\section{Acknowledgements}

This study was supported by grants from the Korea Healthcare Technology R\&D Project, Ministry of Health and Welfare, Republic of Korea (HI10C2020 and A120182).

\section{References}

1 Ratnavalli E, Brayne C, Dawson K, Hodges J: The prevalence of frontotemporal dementia. Neurology 2002;58: 1615-1621.

-2 Neary D, Snowden J, Gustafson L, Passant U, Stuss D, Black S, Freedman M, Kertesz A, Robert P, Albert M, Boone K, Miller B, Cummings J, Benson D: Frontotemporal lobar degeneration: a consensus on clinical diagnostic criteria. Neurology 1998;51:1546-1554.

-3 Piguet O, Hornberger M, Mioshi E, Hodges JR: Behavioural-variant frontotemporal dementia: diagnosis, clinical staging, and management. Lancet Neurol 2011;10:162-172.

-4 Rascovsky K, Hodges JR, Knopman D, et al: Sensitivity of revised diagnostic criteria for the behavioural variant of frontotemporal dementia. Brain 2011;134:2456-2477.

5 Harris JM, Gall C, Thompson JC, Richardson AM, Neary D, du Plessis D, Pal P, Mann DM, Snowden JS, Jones M: Sensitivity and specificity of FTDC criteria for behavioral variant frontotemporal dementia. Neurology 2013; 80:1881-1887. 
6 Hodges JR, Mitchell J, Dawson K, Spillantini MG, Xuereb JH, McMonagle P, Nestor PJ, Patterson K: Semantic dementia: demography, familial factors and survival in a consecutive series of 100 cases. Brain 2010;133: 300-306.

7 Gorno-Tempini ML, Hillis AE, Weintraub S, Kertesz A, Mendez M, Cappa SF, Ogar JM, Rohrer JD, Black S, Boeve BF, Manes F, Dronkers NF, Vandenberghe R, Rascovsky K, Patterson K, Miller BL, Knopman DS, Hodges JR, Mesulam MM, Grossman M: Classification of primary progressive aphasia and its variants. Neurology 2011; 76:1006-1014.

8 Lomen-Hoerth C, Anderson T, Miller B: The overlap of amyotrophic lateral sclerosis and frontotemporal dementia. Neurology 2002;59:1077-1079.

-9 Ibach B, Poljansky S, Barta W, Koller M, Wittmann M, Hajak G; Working Group Geriatric Psychiatry Germany: Patterns of referring of patients with frontotemporal lobar degeneration to psychiatric in- and out-patient services: results from a prospective multicentre study. Dement Geriatr Cogn Disord 2004;17:269-273.

10 Rosso SM, Donker Kaat L, Baks T, Joosse M, de Koning I, Pijnenburg Y, de Jong D, Dooijes D, Kamphorst W, Ravid R, Niermeijer MF, Verheij F, Kremer HP, Scheltens P, van Duijn CM, Heutink P, van Swieten JC: Frontotemporal dementia in the Netherlands: patient characteristics and prevalence estimates from a populationbased study. Brain 2003;126:2016-2022.

$>11$ Hodges JR, Davies R, Xuereb J, Kril J, Halliday G: Survival in frontotemporal dementia. Neurology 2003;61: 349-354.

$>12$ Knopman D, Petersen R, Edland S, Cha R, Rocca W: The incidence of frontotemporal lobar degeneration in Rochester, Minnesota, 1990 through 1994. Neurology 2004;62:506-508.

13 Ikeda M, Ishikawa T, Tanabe H: Epidemiology of frontotemporal lobar degeneration. Dement Geriatr Cogn Disord 2004;17:265-268.

14 Johnson JK, Diehl J, Mendez MF, Neuhaus J, Shapira JS, Forman M, Chute DJ, Roberson ED, Pace-Savitsky C, Neumann M, Chow TW, Rosen HJ, Forstl H, Kurz A, Miller BL: Frontotemporal lobar degeneration: demographic characteristics of 353 patients. Arch Neurol 2005;62:925-930.

15 Mercy L, Hodges JR, Dawson K, Barker RA, Brayne C: Incidence of early-onset dementias in Cambridgeshire, United Kingdom. Neurology 2008;71:1496-1499.

16 Kang SJ, Cha KR, Seo SW, Kim EA, Cheong HK, Kim EJ, Na DL, Jeong JH: Survival in frontotemporal lobar degeneration in a Korean population. Alzheimer Dis Assoc Disord 2010;24:339-342.

17 Ren RJ, Huang Y, Xu G, Li CB, Cheng Q, Chen SD, Wang G: History, present, and progress of frontotemporal dementia in China: a systematic review. Int J Alzheimers Dis 2012;2012:587215.

-18 Ioannidis P, Konstantinopoulou E, Maiovis P, Karacostas D: The frontotemporal dementias in a tertiary referral center: classification and demographic characteristics in a series of 232 cases. J Neurol Sci 2012;318:171-173.

19 Borroni B, Alberici A, Grassi M, Turla M, Zanetti O, Bianchetti A, dalla Volta G, Rozzini R, Gilberti N, Bellelli G, Padovani A: Is frontotemporal lobar degeneration a rare disorder? Evidence from a preliminary study in Brescia county, Italy. J Alzheimers Dis 2010;19:111-116.

-20 Park HK, Na DL, Han SH, Kim JY, Cheong HK, Kim SY, Hong CH, Kim DK, Ku BD, Moon SY, Lee JY, Shim YS, Youn YC, Kim EJ, Kim BC, Park KH, Cha KR, Seo SW, Lee JH: Clinical characteristics of a nationwide hospital-based registry of mild-to-moderate Alzheimer's disease patients in Korea: a CREDOS (Clinical Research Center for Dementia of South Korea) study. J Korean Med Sci 2011;26:1219-1226.

-21 Knopman DS, Kramer JH, Boeve BF, Caselli RJ, Graff-Radford NR, Mendez MF, Miller BL, Mercaldo N: Development of methodology for conducting clinical trials in frontotemporal lobar degeneration. Brain 2008;131: 2957-2968.

-22 Han C, Jo SA, Jo I, Kim E, Park MH, Kang Y: An adaptation of the Korean Mini-Mental State Examination (K-MMSE) in elderly Koreans: demographic influence and population-based norms (the AGE study). Arch Gerontol Geriatr 2008;47:302-310.

23 Reisberg B, Ferris SH, de Leon MJ, Crook T: The Global Deterioration Scale for assessment of primary degenerative dementia. Am J Psychiatry 1982;139:1136-1139.

24 Pantoni L, Inzitari D, Pracucci G, Lolli F, Giordano G, Bracco L, Amaducci L: Cerebrospinal fluid proteins in patients with leucoaraiosis: possible abnormalities in blood-brain barrier function. J Neurol Sci 1993;115: 125-131.

25 Yesavage JA, Brink TL, Rose TL, Lum O, Huang V, Adey M, Leirer VO: Development and validation of a geriatric depression screening scale: a preliminary report. J Psychiatr Res 1982;17:37-49.

26 Fahn S, Elton R: Unified Parkinson's Disease Rating Scale; in Fahn S, Marsden C, Calne D (eds): Recent Developments in Parkinson's Disease. New York, MacMillan, 1987, pp 153-163.

-27 Ahn HJ, Chin J, Park A, Lee BH, Suh MK, Seo SW, Na DL: Seoul Neuropsychological Screening Battery-dementia version (SNSB-D): a useful tool for assessing and monitoring cognitive impairments in dementia patients. J Korean Med Sci 2010;25:1071-1076.

28 Sinoff G, Ore L: The Barthel activities of daily living index: self-reporting versus actual performance in the old-old ( $>$ or $=75$ years). J Am Geriatr Soc 1997;45:832-836.

$29 \mathrm{Ku} \mathrm{H}, \mathrm{Kim}$ J, Kwon E, Kim S, Lee H, Ko H, Jo S, Kim D: A study on the reliability and validity of Seoul-Instrumental Activities of Daily Living (S-IADL). J Korean Neuropsychiatr Assoc 2004;43:189-199.

-30 Kang SJ, Choi SH, Lee BH, Jeong Y, Hahm DS, Han IW, Cummings JL, Na DL: Caregiver-Administered Neuropsychiatric Inventory (CGA-NPI). J Geriatr Psychiatry Neurol 2004;17:32-35. 
31 Kertesz A, Nadkarni N, Davidson W, Thomas AW: The Frontal Behavioral Inventory in the differential diagnosis of frontotemporal dementia. J Int Neuropsychol Soc 2000;6:460-468.

32 Chin J, Kim S, Han N, Kim S, Seo S, Na D: A new rating scale for measuring behavioral change associated with frontal system damage: Frontal Executive Dysfunction/Disinhibition/Apathy Scale (FEDAS). 27th Annu Meet Korean Neurol Assoc, 2008.

-33 Kim H, Na D: Normative data on the Korean version of the Boston Naming Test. J Clin Exp Neuropsychol 1999; 21:127-133.

34 Kang Y, Na D: Seoul Neuropsychological Screening Battery (SNSB). Seoul, Human Brain Research \& Consulting, 2003.

35 Yum T, Park Y, Oh K, Kim J, Lee Y: The Manual of Korean-Wechsler Adult Intelligence Scale. Seoul, Korean Guidance, 1992.

36 Yi H, Chin J, Lee B, Kang Y, Na D: Development and validation of Korean version of Trail Making Test for elderly persons. Dement Neurocogn Disord 2007;6:54-66.

-37 Chow TW, Hodges JR, Dawson KE, Miller BL, Smith V, Mendez MF, Lipton AM; National Alzheimer's Coordinating Center: Referral patterns for syndromes associated with frontotemporal lobar degeneration. Alzheimer Dis Assoc Disord 2005;19:17-19.

-38 Osher JE, Wicklund AH, Rademaker A, Johnson N, Weintraub S: The Mini-Mental State Examination in behavioral variant frontotemporal dementia and primary progressive aphasia. Am J Alzheimers Dis Other Demen 2007;22:468-473.

39 Hodges JR, Graham KS: Episodic memory: insights from semantic dementia. Philos Trans R Soc Lond B Biol Sci 2001;356:1423-1434.

40 Perry RJ, Hodges JR: Differentiating frontal and temporal variant frontotemporal dementia from Alzheimer's disease. Neurology 2000;54:2277-2284.

-41 Carthery-Goulart MT, Knibb JA, Patterson K, Hodges JR: Semantic dementia versus nonfluent progressive aphasia: neuropsychological characterization and differentiation. Alzheimer Dis Assoc Disord 2012;26:36-43.

-42 Rosen HJ, Allison SC, Ogar JM, Amici S, Rose K, Dronkers N, Miller BL, Gorno-Tempini ML: Behavioral features in semantic dementia vs other forms of progressive aphasias. Neurology 2006;67:1752-1756.

43 Bozeat S, Gregory CA, Ralph MA, Hodges JR: Which neuropsychiatric and behavioural features distinguish frontal and temporal variants of frontotemporal dementia from Alzheimer's disease? J Neurol Neurosurg Psychiatry 2000;69:178-186.

-44 Sánchez-Valle R, Forman MS, Miller BL, Gorno-Tempini ML: From progressive nonfluent aphasia to corticobasal syndrome: a case report of corticobasal degeneration. Neurocase 2006;12:355-359.

45 Rohrer JD, Paviour D, Bronstein AM, O'Sullivan SS, Lees A, Warren JD: Progressive supranuclear palsy syndrome presenting as progressive nonfluent aphasia: a neuropsychological and neuroimaging analysis. Mov Disord 2010;25:179-188. 